\title{
¿Hacia una historia global no eurocéntrica?
}

\author{
Perla Patricia Valero Pacheco*
}

Universidad Nacional Autónoma do México, Cidade do México, México

Osterhammel, Jürgen. The Transformation of the World. A Global History of the Nineteenth Century. Patrick Camiller (Trad.). Princeton/Oxford: Princeton University Press, 2014. 1165p.

"El Braudel del siglo XIX" así es como un conocido historiador norteamericano, Jonathan Sperber, titula su reseña sobre la historia global del siglo XIX de más de mil páginas que tenemos en nuestras manos. $\mathrm{El}$ autor de la obra, Jürgen Osterhammel, es un historiador de origen alemán especializado en el estudio de China, coautor de Globalization: A Short History (Princeton University Press, 2005) y autor de Colonialism: A Theoretical Overview (Princeton University Press, 2005) $\mathrm{y}$ de The Transformation of the World. A Global History of the Nineteenth Century, su más reciente obra, que fue traducida al inglés por Princeton University Press en 2014 y al español por Editorial Crítica en 2015 después de cuatro ediciones publicadas en su alemán original, la primera de ellas lanzada en 2009 por la casa editorial C. H. Beck Verlag.

Podría decirse que este libro forma parte de una ola de estudios de 'historia global'
- también denominada historia mundial e interconectada - que ha tomado fuerza desde los años '80 gracias a emblemáticas obras como China Transformed: Historical Change and the Limits of European Experience (Cornell University Press, 1997) de R. Bin Wong y The Great Divergence: China, Europe, and the Making of the Modern World Economy (Princeton University Press, 2000) de Kenneth Pomeranz, así como a los trabajos pioneros de William H. McNeill, como The Rise of the West: A History of the Human Community (Chicago University Press, 1963), que han estudiado los desarrollos civilizatorios del mundo extraeuropeo concluyendo que las diferencias entre Occidente y "el resto" eran menos dramáticas de lo que se piensa, al menos durante el periodo moderno temprano. Osterhammel participa de esta discusión al plantear que esa "gran divergencia" entre Europa y el resto del mundo sucedió en el transcurso del siglo XIX, bajo la eclosión de múltiples interacciones principalmente de cuño económico. No obstante, el propio autor señala que su principal interlocutor no es Pomeranz ni Bin Wong, dos historiadores económicos que estudian la relación EuropaChina bajo el desarrollo de la revolución

DOI - http://dx.doi.org/10.1590/2237-101X017033022

* Doutoranda Programa de Posgrado en Estudios Latinoamericanos de La Universidad Nacional Autónoma do México (PPELA-UNAM) e Colegio de Estudios Latinoamericanos (CELA) de la Facultad de Filosofía y Letras de la Universidad Nacional Autónoma do México (FFyL-UNAM). E-mail: perlapvalero@gmail.com. 
industrial, sino el recientemente desaparecido historiador británico Christopher Bayly, autor también de una historia global del siglo XIX publicada antes que el trabajo de Osterhammel titulada El nacimiento del mundo moderno, 1780-1914 (Siglo XXI España, 2010).

Mientras que Bayly, historiador especializado en la India, hace énfasis en elementos culturales como el nacionalismo, la religión y las prácticas corporales aprehendidos a través de fenómenos individuales pero examinados en perspectiva global, Osterhammel logra escapar del constreñido relato cronológico pormenorizado al privilegiar los grandes temas globales que atravesaron el siglo, y que él identifica como las migraciones, el comercio internacional, el desarrollo urbano, la ciencia, la técnica y la revolución, favoreciendo las temáticas cercanas a la economía y dejando menor espacio al arte y la cultura. El historiador alemán reconoce que, a diferencia de Bayly, su trabajo está "más inclinado al eurocentrismo" debido a la innegable centralidad de Europa en el siglo XIX, la cual es retratada en su obra y de la cual se deriva la verdadera pregunta a contestar: ¿por qué esa península de Eurasia a la que hoy llamamos Europa sometió a buena parte del globo en el transcurso ese siglo XIX?

Osterhammel argumenta que la centralidad de Europa es producto de la época, algo insólito en la historia hasta ese momento y que, como tal, no puede estar ausente de cualquier historia moderna del siglo XIX que pretenda ser global.
Este punto puede resultar controversial para cierta historiografía y teoría social construida desde Asia y América Latina que, simpatizante de las teorías poscoloniales, cuestionan las concepciones "eurocéntricas" de la centralidad de Europa como producto exclusivo de un excepcionalismo, aduciendo que en realidad, incluso antes del siglo XIX fue el establecimiento de colonias de ultramar la condición de posibilidad para el desarrollo de la hegemonía europea. Osterhammel participará indirectamente de este debate al problematizar uno de los puntos flacos de las críticas poscoloniales y decoloniales al eurocentrismo: la existencia de una supuesta idea de Europa como conjunto. Para nuestro autor, esa noción de Europa como conjunto no aparece sino hasta el siglo XIX y no es unívoca, de allí que haga el esfuerzo de llamar a este territorio "península de Eurasia". El autor plantea que la idea de Europa, en realidad, tuvo distintos correlatos en el mapa según la noción geopolítica y por ello habla de distintas Europas: la napoleónica, la romántico-cristiana de la Santa Alianza, la del Congreso de Viena, la de los liberales, la británica y la de los socialistas revolucionarios, además de problematizar la ambigua conceptualización de la época sobre los imperios ruso y otomano, pensados como civilizaciones europeas marginales y como puentes con Asia al mismo tiempo.

Dado que el propósito general de la obra es pintar el retrato de una época desde las interacciones entre el tan estudiado mundo europeo occidental y el resto de la ecúmene, las grandes problemáticas globales son analizadas en tres grandes 
apartados: "Approches", "Panoramas" y "Themes". En el primero se incluyen dos sugerentes capítulos sobre el tiempo ("Time. When was the Nineteenth Century?") y el espacio ("Space. Were was the Nineteenth Century?"), donde Osterhammel reflexiona en torno al problema de la periodización y sostiene que la "experiencia común" del siglo - en términos de Marshall Berman - fue la aceleración, esa "revolución de la velocidad" que se cristalizó en la uniformización de la concepción del tiempo con el establecimiento de los husos horarios y calendarios secularizados en vías de devenir universales. Asimismo, el autor plantea que las concepciones de nuestra geografía moderna son producto del colonialismo decimonónico que "nombró" las partes del globo, resultando en nomenclaturas que no hacen referencia a elementos geográficos producidos por las reflexiones de una ciencia racional, sino que son nombres que reflejan nociones geopolíticas cargadas con visiones "orientalistas".

La segunda parte, "Panoramas", comprende capítulos dedicados a las transformaciones sociales y políticas relacionadas con el desarrollo del capitalismo avanzado. Es decir, los cambios relacionados con las migraciones, la vida material, los muy diversos procesos de urbanización, la subyugación del territorio de los grupos nativos, la construcción de los estados nacionales, la persistencia de los imperios y el despliegue de movimientos transnacionales como las revoluciones $y$ las guerras. De este cúmulo, el capítulo "Revolutions: From Philadelphia vía Nanjing to Saint Petersburg" es particularmente interesante; Osterhammel señala que el XIX es un siglo revolucionario no sólo por la era de la revolución en el mundo Atlántico que lo ve nacer y por el ciclo de revoluciones sociales de la periferia que lo cierran a inicios del siglo XX cronológico. El autor incluye un "estallido de medio siglo" que no se situaría sólo en la Europa de 1848, sino que tendría consecuencias que se entrelazan con las de la Guerra de Crimea para incidir en la eclosión de importantes levantamientos en el mundo asiático como la Rebelión de los cipayos indios de 1857 y la revolución de los taipings en el sureste chino que comienza en 1850; asimismo, este estallido comprendería la Guerra de Secesión norteamericana, que no fue una revolución en realidad pero que trajo consecuencias "verdaderamente revolucionarias", en palabras del autor. No obstante, Osterhammel no profundiza en estos supuestos vínculos ni incluye en el estallido de medio siglo acontecimientos bélicos importantes que sucedieron en América del Sur, levantamientos en el mundo caribeño y en mundo musulmán; este periodo es revisado muy apresuradamente como muchos otros a lo largo de las páginas del libro y es precisamente este uno de los principales problemas de los que adolece la obra, el tratamiento superficial y las conclusiones apresuradas de ciertos temas. A pesar de ello debe celebrarse la riquísima bibliografía especializada y actualizada que el autor pone a la disposición de su lector, especialmente la que refiere trabajos de la historiografía asiática que difícilmente llegan nuestras latitudes. 
El último apartado, "Themes", congrega los capítulos dedicados al desarrollo de la ciencia y la técnica aterrizados en la energía, la industria, las redes comerciales y el trabajo, así como otros más que exploran las dinámicas de la exclusión social y los procesos de secularización. Vale la pena destacar el capítulo dedicado a la religión donde Osterhammel afirma que, a escala global, fueron pocos los lugares donde la religión se convirtió en un sistema funcional diferenciado de la ley, la política y la economía, presentando a la secularización como una anomalía del siglo, especialmente en el mundo asiático. A partir de esta gran atención que el autor dedica a ciertos espacios del globo podemos sostener que, en términos generales, la reflexión más sustantiva se concentra en las relaciones entre Europa occidental y Estados Unidos con partes del globo: Rusia, India, China, Japón, algunos otros lugares de Asia — como el muy diverso mundo islámico — y del Pacífico sur, trabajo para nada desdeńable pero que se ve desbordado frente al tratamiento menor de la relación con las 'otras' periferias: Europa oriental, África y América Latina, lugares que aparecen esporádicamente en las páginas del libro cuando y sólo se tratan temas tradicionalmente representativos de estos territorios. En esta historia del siglo XIX, — el siglo "más europeo" en palabras de Osterhammel —, la relación con Europa occidental es la medida que define a qué espacios prestar atención, de modo que las interacciones que ocurren entre las periferias no aparecen en el, por lo demás, muy buen trabajo de Osterhammel.
Esta obra nos habla de la consolidación del estudio del mundo asiático en la reciente historiografía global, logro que es de celebrarse pero que, a su vez, enuncia las carencias del estudio en perspectiva mundial de otros espacios con menor relevancia política y económica actual, que los deja fuera de los intereses que guían a buena parte de la historia global contemporánea. Asimismo, el trabajo de Osterhammel es un buen ejemplo para reflexionar $y$ discutir en torno a la viabilidad de hacer historia verdaderamente global, una historia que no sólo reconstruya sino analice las interconexiones mundiales entre los centros y las periferias, pero también aquellas que ocurren dentro de las mismas periferias a nivel global, regional y local. Si "toda historia se inclina a ser historia mundial" (Osterhammel, p. XV) como sentencia nuestro autor, los retos metodológicos parecen rebasarnos, pues alcanzar el equilibrio entre la investigación multi-temática exhaustiva con el tratamiento de escalas espaciales y temporales globales sin prescindir, al mismo tiempo, de las interconexiones a nivel local, nos aparece como una tarea infranqueable.

No nos encontramos un problema estrictamente nuevo, pues "Una historia general del mundo es necesaria pero no posible en el estado actual de la investigación..." como ya lo señalaba Von Ranke en 1869, "Pero necesitamos no desesperar: la investigación particular es siempre instructiva cuando produce resultados, y en ninguna parte más que en la historia, donde incluso en los rincones más profundos siempre encuentra un 
elemento vivo con significado universal" (Osterhammel, p. 902). Con esta frase del padre de la historiografía alemana moderna, Osterhammel abre sus conclusiones donde esboza las "características del siglo", o aquello que encuentra como la esencia común del periodo. En primer lugar un crecimiento asimétrico fundamentado en la eficiencia, tanto del trabajo como de los nuevos mercados intercontinentales, de la industrialización de las fuerzas armadas y la burocratización; en segundo lugar, una nueva forma de movilidad de personas y mercancías; en tercero, una tendencia a la densidad de las transferencias entre culturas, que oscila entre el intercambio y el imperialismo cultural; en cuarto lugar, la tensión entre igualdad y jerarquía; y en quinto y último lugar, la emancipación y la participación política representativa con todos sus asegunes.

En tan pocas páginas se torna difícil hacerle justicia a una obra de gran calado como The Transformation of the World, aunque tal vez su virtud más importante descanse en la motivación de regresar a la historia total, un objetivo que se antoja casi imposible pero que, a nuestro parecer, es el motor que debe empujar los esfuerzos de la nueva historia global. 